\title{
Lixo, resíduos sólidos e reciclagem: uma análise comparativa de recursos didáticos
}

\section{Garbage, solid waste and recycling: a comparative analysis of teaching resources}

\author{
Heloisa Sisla Cinquetti**
}

\begin{abstract}
RESUMO
Este trabalho faz uma análise comparativa do tema dos resíduos sólidos em recursos didáticos impressos (livros didáticos, livros paradidáticos e artigos de revista) dirigidos ou assimiláveis pela faixa etária das séries iniciais do ensino fundamental. $\mathrm{O}$ destaque da análise é dado à natureza dos conhecimentos sobre resíduos sólidos e lixo veiculados nos textos. Discute-se a problematização da quantidade de lixo, o conceito e tempos de degradação dos materiais, a reciclagem, proposta como solução preferencial para a questão, e algumas inadequações e ausências encontradas nos recursos didáticos. Constataram-se problemas quanto à natureza dos conhecimentos veiculados ou ausentes nos três tipos de recursos didáticos examinados. Esta análise pode contribuir para uma perspectiva mais crítica de educadores envolvidos com a temática ambiental e em particular com o tema dos resíduos sólidos.

Palavras-chave: educação ambiental, resíduos sólidos, reciclagem.
\end{abstract}

${ }^{*}$ Este trabalho teve o financiamento da Capes e do CNPq e uma versão inicial (resumida) foi apresentada e encontra-se nos Anais do VII Encontro Perspectivas do Ensino de Biologia/ I Simpósio Latino-Americano da International Organization for Science and Technology Education, realizado em São Paulo, em fevereiro de 2000.

Muito do que aprendi sobre minimização de resíduos e intervenções educativas deveu-se ao atendimento sempre solícito, paciente e competente do Programa USP Recicla, em especial da educadora Patrícia Cristina Silva Leme, a quem agradeço as conversas, os materiais, as indicações de leituras e sugestões para uma versão inicial deste texto.

** Doutora, pesquisadora e professora junto ao Departamento de Metodologia de Ensino, da Universidade Federal de São Carlos. 


\begin{abstract}
This article makes a comparative analysis of the subject of solid waste in printed didactic resources (textbooks, children's books and magazine articles) addressed to or possible of being understood by students of Elementary school. The focus of the analysis is given to the nature of the knowledge about solid waste present in the texts. We discuss the problem of amount of garbage, recycling proposed as the main solution to this problem, the concept of decaying of materials and some mistakes and absences found in the texts. We identified problems related to the nature of knowledge or absences in the three types of texts. This analysis may contribute to enhance a more critical perspective for educators involved with environmental education and particularly with the subject of solid waste, when selecting didactic resources or implementing educational programs.
\end{abstract}

Key-words: environmental education, solid waste, recycling.

\title{
Introdução
}

O presente trabalho tem por objetivo realizar uma análise comparativa de materiais didáticos impressos, para as séries iniciais do ensino fundamental, sobre uma temática ambiental urbana cada vez mais presente nos trabalhos de educação ambiental nas escolas, a do lixo e dos resíduos sólidos ${ }^{1}$. Se é positivo o fato de o tema estar sendo desenvolvido, há também sinais de que é preciso repensar alguns dos princípios das abordagens veiculadas, conforme indicam blauth (1994) e grimberg e blauth (1998). Pensamos que os recursos didáticos representam tanto matizes do que educadores e outros setores da sociedade pensam e comunicam sobre um tema específico, quanto concepções sobre educação, ensino-aprendizagem, ciência e meio ambiente, como já demonstraram autores que fizeram análises de livros didáticos (вONAZZI; ECO, 1980; NOSELla, 1980; e PRETTO, 1995). Neste sentido, nossa

${ }^{1}$ Conforme proposto por LOGAREZZI (2003), diferenciamos lixo e resíduos. Enquanto os resíduos são as sobras das atividades humanas passíveis de reciclagem, o lixo é o que remanesce dessas atividades e é jogado fora. Ao primeiro associamos valores sociais, econômicos e ambientais, ao passo que no segundo nenhum desses valores potenciais é mantido. 
contribuição é colocar em cheque informações e valores sobre o tema, na forma em que se apresentam para a escola.

A temática ambiental vem sendo introduzida na escola brasileira nas últimas décadas, em decorrência de iniciativas de diferentes setores da sociedade, que vêm ampliando os debates. Justamente devido à introdução recente, há ainda poucas análises de materiais didáticos (TRAJBER; MANZOCHI, 1996; SOSSAI et al., 1997) e nenhuma específica sobre a questão dos resíduos sólidos.

As preocupações que originaram este artigo fizeram parte da fase inicial de nossa pesquisa de doutorado, que investigou as abordagens atribuídas por professoras ao tema do lixo e dos resíduos, assim como os processos de desenvolvimento profissional, a partir de intervenções tendo como foco a temática ambiental e os resíduos sólidos. Nas intervenções com as professoras, uma das atividades propostas era a de analisar criticamente os recursos didáticos aos quais tinham acesso. Antes de propormos este exercício às professoras, consideramos importante empreender nossa própria análise.

As questões que norteiam este trabalho são: De que forma os conhecimentos e os debates que se têm hoje sobre este tema ambiental estão refletidos nos recursos didáticos? Ocorrem incorreções e informações desatualizadas? Há aspectos importantes que não estão presentes nos materiais? Que comparações podem ser feitas entre os três tipos de recursos impressos usualmente empregados pelos professores?

Nosso ponto de partida para a análise é a abordagem da temática ambiental, conforme sugerida por CARVALHO $(1989$; 1996) e CARVALHO et al. (1996), relativa às dimensões dos conhecimentos, dos valores (éticos e estéticos) e da participação política. Dentre elas, destacaremos neste trabalho principalmente a dos conhecimentos veiculados sobre a questão do lixo, deixando de abordar com mais centralidade os aspectos relativos a valores e participação política. Entendemos, porém, que a análise em separado das diferentes dimensões nem sempre é possível ou recomendável e, portanto, algumas discussões referentes a alguns destes aspectos foram incluídas, como é o caso por exemplo da crítica ao consumo insustentável.

\section{Procedimentos}

Foram analisados três tipos de recursos didáticos: livros didáticos, livros paradidáticos e artigos de revistas. Todos podem ser compreendidos pela 
faixa etária que abrange as quatro séries iniciais do Ensino Fundamental. A facilidade de acesso dos professores aos recursos didáticos foi o principal critério para a seleção da amostra, composta por livros encontrados em escolas da rede estadual e municipal e bibliotecas públicas de São Carlos, São Paulo.

Optou-se por não restringir a análise aos livros didáticos, pois é cada vez freqüente, no estado de São Paulo e na rede municipal da cidade pesquisada, a compreensão de que as professoras devam utilizar outros recursos em vez de ou além dos livros didáticos. É comum a sugestão de inclusão na sala de aula dos livros paradidáticos e da utilização de artigos de revistas e outros textos que não foram elaborados para o uso exclusivo em sala de aula.

As edições analisadas dos livros didáticos $(n=5)$ são todas posteriores a 1995. Os livros são dirigidos a segundas e terceiras séries, faixas etárias em que encontram-se a maior parte dos livros abordando o tema do lixo ou dos resíduos. Foi incluído só um volume por coleção. Apenas os tópicos referentes ao lixo, aos resíduos e à reciclagem foram objeto de análise. Do total dos livros, apenas um (LD1, conforme relação abaixo) é de Língua Portuguesa e os demais são livros didáticos de Ciências. A análise dos livros didáticos foi restrita à parte destinada aos alunos, não incluindo as orientações aos professores. Por livro didático entendem-se aqueles que destinam-se exclusivamente ao uso em sala de aula, tendo a professora como intermediária, seguem um plano curricular de determinada disciplina para uma determinada série, por um ano letivo, e costumam conter exercícios ou questões a serem executados pelo aluno.

Os livros didáticos analisados foram:

1. MIRANDA, Claudia. Linguagem Viva, v. 2, Ática, 1998. (LD1)

2. SANTOS, M. L.; BRANDO, A. F. R.; Caldeira, A. M. Desvendando o mundo - Ciências, $2^{\mathrm{a}}$ série. Ed. do Brasil, 1996. (LD2)

3 CORREIA, M. E.; Galhardo, M. Como é fácil!!, $3^{\text {a }}$ série. Scipione, 1995. (LD3)

4. PORTO, A.; RAMOS, L.; GOULART, S. Terra - Planeta Vida, $3^{\text {a }}$ série. Expressão, 1998. (LD4)

5. JAKIEVICIUS, M. Ciências - Atividades Integradas, $3^{\text {a }}$ série. Scipione, 1999. (LD5)

Entendem-se por paradidáticos os livros que não se destinam ao uso exclusivo em sala de aula e que não possuem a abrangência de uma programação curricular, representando em geral uma parte dela. Vêm sendo usados por professoras como um de seus principais recursos didáticos subsidiários, ou como complementares ao livro didático. Os paradidáticos de nossa 
amostragem foram editados na década de 1990, à exceção do PD5. O público-alvo dos paradidáticos é mais amplo, se comparado aos livros didáticos, dirigindo-se a diferentes faixas etárias, o que poder gerar dificuldades com as quais a professora deverá lidar. É o caso dos paradidáticos PD2, PD3 e PD5, que veiculam alguns conceitos difíceis de serem compreendidos por alunos de algumas das séries iniciais. Não consideramos esta característica um problema, por entendermos que os paradidáticos informativos, como os citados, são livros de consulta e comportam diferentes graus de compreensão por parte dos alunos. Ajudam neste sentido as estratégias didáticas que estes recursos utilizam, para facilitar a comunicação de suas mensagens, tais como o emprego de cores, quadros, tabelas, figuras e ilustrações.

Segue a lista dos paradidáticos $(\mathrm{n}=5)$ :

1. BRANCO, S. M. O saci e a reciclagem do lixo, Moderna, 1994. (PD1)

2. HARE, T. Reciclagem. Melhoramentos, 1993. (PD2)

3. JAMES, B. Lixo e Reciclagem. Scipione, 1993. (PD3)

4. ROCHA, J. G. Enquanto o vento levar. Secretaria do Meio Ambiente do Estado de São Paulo, 1998. (PD4)

5. Lixo, onde colocar isso tudo? Artigo não assinado publicado na Revista Ciência Hoje das Crianças, out. 1989, p. 6-9. (PD5) ${ }^{2}$

Adotou-se a divisão dos paradidáticos em informativos (PD2, PD3 e PD5) e de ficção (PD1 e PD4). Três são nacionais (PD1, PD4 e PD5) e dois são traduções (PD2 e PD3).

Os artigos de revistas são de um semanário de atualidades para adultos (Revista Veja), cujo conteúdo já pode ser compreendido pela faixa etária de $2^{\mathrm{a}}$. e $3^{\mathrm{a}}$. séries. Seu reduzido número na amostra $(\mathrm{n}=2)$ deve-se à dificuldade de selecionar artigos que foram escritos para adultos, mas que possam ser compreendidos, mesmo que parcialmente, por alunos de 7 a 10 anos. Embora com uma pequena amostra, optou-se por incluir os artigos de revista, pois se não foram elaborados para serem usados em sala de aula, seu uso para este fim vem sendo cada vez mais recomendado. Seriam estes artigos de fato mais atualizados e com informações e valores mais confiáveis, para ensinar e aprender sobre temas ambientais, do que os livros?

Os artigos de revista escolhidos foram:

\footnotetext{
${ }^{2}$ Optamos por incluir dentre os paradidáticos o texto da Ciência Hoje das Crianças $(\mathrm{CHC})$ por julgarmos que suas características são mais próximas deste tipo de recurso do que de artigos de revista.
} 
1. GONÇALVES, Daniel Nunes. Sujeira recorde. Revista Veja, jun. 1997, p. 81. (R1)

2. LIMA, Maurício. Um bebê $=25$ toneladas de lixo. Revista Veja, mar. 1999, p. 60-62. (R2)

\section{Análise dos dados}

Ao abordar a questão do lixo, pensamos que os materiais didáticos deveriam incluir três aspectos básicos: a discussão sobre suas raízes, sobre as consequiências em termos de impactos ambientais e sobre as alternativas quanto ao tratamento de resíduos e à disposição do lixo (CINQUETTI; CARVALHO, 2003). Analisamos a seguir cada um destes aspectos. Iniciaremos sempre apresentando, de forma breve, nosso posicionamento sobre os aspectos acima mencionados, pautados pela literatura, para em seguida mostrarmos como tais elementos encontram-se ou não presentes nos materiais, e de que maneiras. Acrescentamos ainda, numa última parte da análise dos dados, alguns comentários sobre os recursos da amostra, relativos a questões formais e conceituais, que julgamos não poderem ser ignoradas.

\section{Resíduos: identificando o problema e suas raízes}

As raízes da questão dos resíduos remontam à produção dos bens que serão eventualmente descartados. É o consumo de bens o responsável pelos impactos ambientais que podem ser identificados na questão dos resíduos. $\mathrm{O}$ consumo desigual entre países e pessoas ricas e pobres, o consumo excessivo, desencadeando ou não o desperdício, e o aumento do consumo de embalagens, de produtos não degradáveis, descartáveis ou tóxicos vêm sendo apontados pela literatura ambientalista (AGENDA XXI, 1994; FIGUEIREDO, 1995) como os principais problemas referentes à questão. Veremos, a seguir, como esses fatores vêm sendo abordados nos recursos didáticos.

A maioria dos materiais aborda a questão problematizando o crescente aumento de quantidade de lixo produzido e discute alternativas possíveis para 
o encaminhamento de resíduos ou para a disposição do lixo. Os autores desses materiais identificam, portanto, um elemento central da discussão sobre o tema em pauta, segundo a literatura. Três recursos analisados não tocam na questão do aumento da quantidade de lixo: LD3, PD4 e PD5.

Destes, o LD3 é o único que apresenta uma abordagem que se reduz à importância de existir a coleta de lixo e do seu correto acondicionamento em sacos plásticos. Sabemos que a ausência de coleta ainda é um problema ambiental e sanitário no Brasil. As áreas rurais dificilmente possuem coleta de lixo, que por vezes também é ausente em algumas áreas urbanas. Apesar da dificuldade em precisar a quantidade de lixo destinado aos lixões clandestinos, terrenos baldios e rios ou à queima, sabe-se que ela ainda é bastante significativa (a AGENDA XXI indica que metade da população urbana nos países em desenvolvimento não tem serviços de coleta de lixo). Embora a menção à necessidade da coleta seja importante em nossa realidade, não se justifica a redução do tema apenas a este tópico e, no caso do LD3, a apenas uma página, sob o título "Saneamento Básico".

Uma questão importante sobre o aumento da quantidade de lixo referese às suas raízes. Muitas fontes apontam o aumento da população e do consumo como causadores do aumento, o que é uma informação limitada. Sabe-se que os países e as pessoas não consomem de maneira uniforme. Os países e as pessoas ricas consomem mais, enquanto outros estão excluídos do consumo de bens básicos. Como em nosso país (e no planeta) a distribuição de renda, e por conseguinte do consumo, é muito desigual, pensamos que esta discussão não poderia ficar de fora. Apenas dois dos recursos didáticos tangenciaram o tema. No LD4 há menção ao modelo societário "que prima pelo novo, pelo supérfluo e pelo descartável" (p. 131). No PD3 a associação é mais direta, com a responsabilização do Capitalismo pelo incentivo ao consumo: "Vivemos numa sociedade que consome, ou usa, muitos recursos. É a chamada 'sociedade de consumo', existente nos países capitalistas... Esse estilo de vida consome muitos recursos naturais." (p. 10)

O mesmo livro é o único a discutir o consumo desigual, ilustrado com uma balança, em que 33\% da população da Terra usam $85 \%$ dos recursos naturais, enquanto $67 \%$ das pessoas usam apenas $15 \%$ dos recursos terrestres.

Os exemplos citados em PD3 e LD4 remetem à raiz da questão dos resíduos, assim como da questão ambiental. Foram os únicos que fizeram menção ao modelo social e econômico, discussões que estiveram, portanto, raramente presentes nos materiais didáticos.

Ainda quanto ao consumo, buscou-se saber se os recursos didáticos apontavam o consumo de bens dentre os principais fatores do aumento de resíduos. 
Surpreendentemente, apenas cinco (LD5, PD2, PD3, R1 e R2) dos doze recursos analisados abordam a questão do consumo de bens, indicando que uma relação que parece ser tão direta, entre consumo e aumento na geração de lixo, nem sempre é explicitada como deveria.

Foram ainda mais raros aqueles materiais que apontaram de forma crítica elementos que podem ser associados ao consumismo. Além do exemplo já mencionado no LD4, indicando o consumo de novidades, supérfluos e descartáveis como desencadeadores do aumento de lixo, o PD2 e o PD3 abordam o problema do crescimento dos produtos descartáveis (p. 8, PD2) e levantam a questão do desperdício e do excesso de embalagem de certos bens (p. 8, PD2 e p. 12, PD3).

\section{A questão do lixo e suas conseqüências}

Examinaremos nesta seção a questão dos impactos ambientais responsáveis pela degradação ambiental, destacando aqueles mais diretamente relacionados à produção de bens e disposição de lixo. Dedicaremos especial atenção ao desenvolvimento do conceito de decomposição nos materiais didáticos, por entendermos que este é um conceito fundamental para a compreensão dos impactos causados pela disposição de lixo.

São hoje relativamente bem conhecidos os impactos ambientais ligados à produção de resíduos e ao descarte de lixo. Muitas das questões ambientais do planeta decorrem da produção dos bens. As mais freqüentemente mencionadas nos livros de referência sobre resíduos, nos materiais didáticos e manuais para o professor são o uso e conseqüente esgotamento de recursos naturais ${ }^{3}$, a produção e o uso de energia (majoritariamente hidrelétrica no caso do Brasil), e a poluição (ar, água ou solo). Embora menos mencionados, devem ser incluídos os impactos causados pela produção de alimentos, que compõem, junto com madeiras e tecidos, $65 \%$ dos resíduos do lixo domiciliar brasileiro (JARDIM et al., 1995). Dentre os impactos causados, no Brasil, pela agricultura, pecuária e produção industrial de alimentos, temos o efeito

\footnotetext{
${ }^{3}$ Em particular os não-renováveis, como petróleo, matéria-prima dos plásticos e metais, mas também os renováveis, como água, madeira e areia (usada na fabricação do vidro).
} 
estufa ${ }^{4}$, a desertificação ${ }^{5}$ e a perda da biodiversidade, além da já citada poluição e da contaminação, especialmente das águas.

Quanto aos impactos da disposição de lixo, podem ser considerados os originados pelo descarte individual inadequado, assim como a disposição realizada por empresas ou municipalidades. A disposição inadequada em vias públicas, rios e outros locais impróprios pode ocasionar degradações estéticas (poluição visual), agravamento das enchentes e a disseminação de doenças. Quando não há coleta domiciliar, recomenda-se que os resíduos de alimentos sejam compostados e que o lixo seja enterrado ${ }^{6}$ ou transportado até postos onde ocorra a coleta. Recomenda-se, ainda, que o lixo não seja queimado.

Já o lixo coletado por governos municipais ou empresas deve ser disposto em aterros sanitários ${ }^{7}$. Somente $13,8 \%$ dos municípios brasileiros dispõem o lixo em aterros sanitários (IBGE, 2003). Há uma tendência de esgotamento dos aterros (cuja vida útil é curta) e de escassez de áreas destinadas à sua construção. É cada vez mais difícil encontrar áreas para aterros perto dos centros urbanos (FIGUEIREDO, 1995). Quanto mais distante de uma cidade o aterro, maior será o consumo de combustíveis para o transporte do lixo, aumentando o impacto da disposição (sem mencionar a elevação dos custos). Se o destino dado pela Prefeitura for inadequado, o lixo será destinado à disposição a céu aberto (lixão) ${ }^{8}$ ou a aterros controlados ${ }^{9}$. Para ambos o pior impacto ambiental é o mesmo: a contaminação das águas dos lençóis freáticos

${ }^{4}$ Causado pela liberação de gases que superaquecem a Terra, principalmente o dióxido de carbono, proveniente da queima de combustíveis fósseis usados nas indústrias e veículos. Outros gases também contribuem para o efeito estufa, como os clorofluorcarbonetos, gerados em certos processos, e o gás metano, liberado pela decomposição de matéria orgânica.

${ }^{5}$ Sobre especificidades deste problema no Brasil, ver EMBRAPA, 1996.

${ }^{6}$ Há materiais que contêm substâncias perigosas e que não se recomenda serem enterrados, pois podem contaminar as águas subterrâneas ou o solo, como pilhas, baterias, lâmpadas fluorescentes, tintas, embalagens de agrotóxicos e frascos de aerossóis. Tais materiais só deveriam ser dispostos em aterros sanitários funcionando corretamente ou aterros específicos para produtos perigosos (JARDIM et al., 1995).

${ }^{7}$ Um aterro sanitário é uma obra de engenharia. O solo é geralmente escavado e preparado com uma manta de plástico grosso e uma camada de argila, para deixá-lo impermeável. Após a deposição do lixo, este é compactado por máquinas e coberto com terra ou outro material inerte. Há canaletas para escoamento das águas pluviais e o chorume deve ser escoado para tanques, com solo também impermeabilizado, e submetido a tratamento. Os gases gerados da decomposição dos resíduos são liberados por tubulações em que são queimados. É preciso atender a especificações quanto ao local de construção do aterro, mantendo distância de leitos de rios e córregos.

${ }^{8}$ Os lixões a céu aberto recebem os resíduos sem destinar a eles nenhum tipo de proteção do solo, ar e água.

${ }^{9}$ No aterro controlado, o lixo é compactado e coberto com terra ou material inerte. Mas não há impermeabilização do solo, escoamento de águas pluviais e tratamento do chorume. 
ou pluviais. Os lixões e aterros controlados são também responsáveis pela poluição do solo, do ar e visual.

Como os materiais didáticos analisados trataram das principais questões colocadas acima? Tentaremos, a seguir, discutir as adequações e inadequações das abordagens, com base na literatura disponível.

Quanto à disposição do lixo, uma primeira indagação diz respeito a se os recursos discutem esta questão. Oito deles (LD1, LD2, LD3, LD4, PD1, PD2, PD4 e R1) não discutem as possíveis alternativas para a disposição de lixo. Esta ausência é preocupante, especialmente nos livros didáticos e paradidáticos, que teriam por obrigação ao menos mencionar que este é o encaminhamento mais indicado para a maioria dos municípios brasileiros. Dos quatro recursos que fazem esta discussão, nenhum propõe o aterro sanitário como a alternativa ambientalmente mais indicada para as atuais condições brasileiras.

Em três dos quatro materiais didáticos que discutem as alternativas de disposição depreende-se ou afirma-se que as usinas (de compostagem, de transformação ou de energia) são indicadas como as melhores alternativas para a disposição do lixo:

Nessas usinas (de compostagem), vidro, plástico e metal são separados a fim de serem enviados para a reciclagem. Os restos de alimentos são tratados para virarem adubo. LD5 (p. 78).

O melhor tratamento é colocar o lixo em usinas de transformação. (PD5, p. 6).

A saída ideal está na reciclagem e na montagem de usinas geradoras de energia. (R2, p. 62).

Quanto à assim designada usina de compostagem, a apresentação do LD5 ignora investigações recentes (GRIMBERG; BLAUTH, 1998; SILVA, 1997) que apontam problemas relacionados a este tipo de usina, tais como o baixo índice de aproveitamento dos resíduos (1,5\% no caso da Usina de Vila Leopoldina em São Paulo), o baixo valor de mercado dos resíduos sujos e contaminados, a presença de vidro e metais (incluindo a contaminação por metais pesados oriundos de pilhas e baterias) no composto orgânico e o alto índice de rejeitos (materiais não recicláveis que têm como destinação final o lixão ou aterro). A esta lista pode também ser acrescido o problema da falta de envolvimento da população, que ocorre quando há o descarte e coleta seletivos, mas não quan- 
do o lixo é encaminhado a este tipo de usina. É difícil levantar vantagens deste tipo de encaminhamento de resíduos, já que essas usinas nem viáveis economicamente são. Não há, por exemplo, uma usina brasileira que seja auto-sustentável financeiramente (GRIMBERG; BLAUTH, 1998, p. 19).

Ainda quanto à disposição do lixo, um livro didático sugere um destino inadequado para o lixo: "Nos lugares onde não há serviço de limpeza pública, o lixo deve ser enterrado em buracos fundos ou queimado." (p. 164, grifo nosso).

Presta um desserviço este livro ao propor a prática da queima do lixo, infelizmente tão disseminada, que é proibida por lei no Brasil (Portaria $\mathrm{n}^{\circ} .53$ de 01/03/1979, do Ministério do Interior), e pode causar poluição do ar, como corretamente aponta o PD5: "Muitas vezes o lixo é queimado, provocando poluição atmosférica pelo lançamento de partículas e de fumaça no ar." (p. 6).

Quanto ao impacto ambiental ocasionado pela produção de bens, a maioria dos recursos analisados (seis em doze) faz referência ao aspecto mais evidente destes impactos, que é o esgotamento de recursos naturais, como nos exemplos:

Para fazer uma tonelada de papel, são derrubados vinte eucaliptos, que demoram sete anos para crescer. (LD1, p. 215).

Entretanto as reservas de petróleo só poderão durar mais 60 anos se ele continuar sendo consumido com a velocidade atual. (PD2, p. 5).

Um número maior de recursos (oito) menciona impactos ambientais causados pela disposição de resíduos. Destes, a maioria cita o principal impacto, que é o risco de contaminação das águas (LD5, PD1, PD2, PD3, PD5 e R2). Outros impactos ambientais ou problemas mencionados foram a poluição do solo (LD5), a crescente escassez de espaços para a disposição (PD5), a possibilidade de explosão de gases (PD3), a contaminação por metais pesados (R1 e R2) e o elevado tempo de degradação dos resíduos. Dedicaremos uma atenção maior à discussão dos dois últimos tipos de impactos ambientais.

Só os artigos de revista, como citado acima, mencionam a contaminação por metais pesados nos resíduos domésticos, evidenciando a ausência deste tema nos livros didáticos e paradidáticos. Mesmo os paradidáticos informativos, que trazem informações mais completas e aprofundadas, detendo-se inclusive em resíduos tóxicos de outras origens (industrial, agrícola e radioativo), não mencionam a contaminação do lixo doméstico por substân- 
cias tóxicas. Seria importante levantar a questão, citando por exemplo o caso das pilhas e baterias, que tem sido o mais divulgado e, mais recentemente, foi objeto de legislação que proíbe o descarte e responsabiliza o produtor pela destinação final.

Todavia, como muitos outros aspectos sobre o lixo compreendido como tema ambiental, o mérito da abordagem convive na $\mathrm{R} 2$ com o descrédito de um erro, quando ilustra com uma lâmpada incandescente o quadro Inimigos da natureza, indicando que este tipo de lâmpada contém mercúrio, o que é falso. As lâmpadas fluorescentes é que contêm mercúrio, metal pesado que pode infiltrar-se no solo, atingir o lençol freático, entrar na cadeia alimentar e causar contaminação em seres vivos, podendo provocar mutações genéticas em seres humanos (BONFIGLIOLI; LISBOA, 1997).

Uma informação comumente veiculada nos recursos didáticos sobre lixo refere-se ao tempo de degradação dos diferentes materiais no ambiente. Dos materiais analisados, quatro (LD1, LD5, PD4 e R2) incluem esta informação e os dados obtidos estão na tabela 1 .

TABELA 1 - TEMPO DE DEGRADAÇÃO DE MATERIAIS EM QUATRO RECURSOS DIDÁTICOS

\begin{tabular}{|l|l|c|c|c|}
\hline & \multicolumn{1}{|c|}{ LD1 } & LD5 & PD4 & R2 \\
\hline Vidro & 4.000 anos & 5.000 anos & + de 10.000 anos & 10.000 anos \\
\hline Lata & 10 anos & - & - & - \\
\hline Lata alumínio & - & 400 anos & - & 100 anos \\
\hline Tecidos & 100 a 400 anos & - & - & - \\
\hline Tecido algodão & - & 4 meses & - & - \\
\hline Papel & 3 meses & 4 semanas & $*$ & 100 anos \\
\hline Plástico & + de 100 anos & até 450 anos & + de 100 anos \\
\hline
\end{tabular}

(* alguns meses, ... poucos anos) PD4, p. 22

A primeira observação refere-se à disparidade dos tempos de degradação do vidro (4.000 a mais de 10.000 anos), do metal (100 a 400 anos) e do plástico (100 a 450 anos) fornecidos pelas quatro fontes. Tais disparidades refletem a dificuldade de precisar o tempo de degradação dos materiais. Segundo o boletim CEMPRE INFORMA (1989), é difícil indicar com precisão quanto tempo os materiais demoram para se degradar, pois isto depende do tipo de composição dos materiais (o tipo de plástico, metal, papel, restos de comida, etc.) e de fatores ambientais (temperatura; umidade; exposição aos raios sola- 
res; $\mathrm{pH}$ e características geológicas do solo; no caso de ambiente aquático, se é rio, manguezal ou oceano e se é água doce ou salgada; no caso de locais de deposição de resíduos, se é lixão ou aterro).

Quanto ao papel, se a defasagem dos tempos não é tão grande, questionase o dado de que se degrada em até 3 meses ou mesmo alguns anos. Os estudos do antropólogo W. RATHJE (1989), que escavou aterros sanitários nos Estados Unidos, desafiaram muito do conhecimento que temos sobre lixo, inclusive sobre o tempo que o papel leva para se decompor. Ele encontrou, em escavações feitas em 1989, um jornal de 1952, ou seja, com 37 anos de idade e ainda legível. Além do papel, muitos restos de comida também foram encontrados inteiros: espiga de milho, alface, pão e cachorro-quente (RATHJE, 1989; 1991). Este pesquisador verificou também que, na maioria dos aterros americanos que escavou, a maior parte do lixo não decomposto da década anterior era formada por papel (40 a 50\%) e restos de comida, até então julgados como sendo de fácil decomposição, enquanto em um dos aterros pesquisados (Fresh Kills, em Staten Island, Nova York), papéis e restos de comida decompunham-se com maior facilidade, provavelmente devido à umidade ali presente (RATHJE, 1991).

Mas se encontramos tantas disparidades nos tempos de degradação, será que este aspecto deveria ser mencionado nos recursos didáticos? Pensamos que o mais importante é que os alunos saibam quais materiais degradam-se mais rápida ou lentamente diante das mesmas condições, pois esta informação, aliada aos conhecimentos sobre as condições de reciclagem dos resíduos em cada região, pode determinar, por exemplo, a escolha de tipos de embalagens de alimentos mais ou menos degradantes para o ambiente. Seria importante a experimentação destes tempos de degradação, como, por exemplo, enterrar objetos e verificar seus estados após um período de tempo, o que não é proposto nos livros examinados.

Um cuidado no tratamento destes dados sobre os tempos de degradação seria informar a fonte. A matéria da R2 informa como suas fontes o economista Sabetai Calderoni e o 5 Elementos, Instituto de Educação e Pesquisa Ambiental; o LD5 tem como fonte o artigo da R1 (que por sua vez não cita suas fontes) e apesar de o LD1 não revelar sua fonte, os dados mostrados são exatamente iguais (à exceção da estimativa feita para os tecidos, que tem outra origem) aos de artigo publicado na revista Superinteressante, de julho de 1993, que, entretanto, também não indica sua fonte. O mais indicado seria avaliar a confiabilidade das fontes, dando preferência àquelas resultantes de pesquisas científicas publicadas e com o maior grau possível de independência em relação a qualquer indústria que tenha algum tipo de interesse relacionado ao mercado de produtos recicláveis. 
Uma outra questão a ser examinada quanto à decomposição/degradação é como este conceito-chave é ou não apresentado e desenvolvido nestes recursos. Quase todos os recursos analisados mencionam ou explicam um dos dois termos. Examinaremos o PD3, que é, ao nosso ver, o que apresenta o conceito de decomposição integrando os conceitos ecológicos e empregando uma apresentação dinâmica e atraente. Este livro inicia aproximando a explicação a ser dada com o pensamento do aluno: $O$ que acontece com os pássaros e animais quando morrem? Para onde vão as folhas que caem das árvores? Se há o emprego de termos de difícil compreensão, como elementos químicos, nutrientes, bactérias e fungos, os exemplos dados e a figura com legendas, que ilustra a decomposição numa floresta, podem clarear os pontos básicos do conceito: animais e folhas mortos são separados em pequenas partes e se transformam em matérias-primas, que vão fazer parte do solo, propiciando o nascimento e crescimento de plantas e animais, num "interminável ciclo de morte, decomposição, nova vida e crescimento" (p. 6). Um dos conceitos mais importantes a ser compreendidos desde esta faixa etária é de que a matéria continua a existir apesar de mudar de uma forma para outra, ou mudar de lugar. Ter contato e vivenciar de diferentes formas o ciclo na natureza e a reciclagem de materiais ajuda na compreensão de que a matéria se transforma, mas não desaparece no ambiente, concepção corrente no pensamento de estudantes do ensino fundamental (AMERICAN ASSOCIATION FOR THE ADVANCEMENT OF SCIENCE, 1993, p. 119 e 343). Cabe destacar positivamente a definição dada no glossário do mesmo PD3 de que decompor é "separar os elementos de uma matéria morta” (p. 44), pois é a idéia de separação e não de desaparecimento ou destruição que está presente no conceito de decomposição.

Ainda quanto à apresentação do conceito de decomposição, destacamos positivamente também o quadro Para alguma coisa serve o lixo, do PD5. Apesar da linguagem (nutrientes, sais minerais, bactérias, fungos, restos orgânicos, etc.), nem sempre adequada para a faixa etária, as informações podem ser compreendidas com a ajuda da professora. $\mathrm{O}$ quadro começa bem, falando do importante papel dos microrganismos na decomposição. Afirma que, ao contrário do que é pensamento corrente, "nem todos os microrganismos que proliferam no lixo fazem mal". Prossegue, usando desta vez uma linguagem apropriada, explicando que "restos de alimentos... (e) certos materiais de origem biológica (vegetal e animal) também são decompostos...”, evitando o termo "orgânico", que diz pouco (ou nada) para esta faixa etária.

Segundo trivelato (1998), alunos de 7 a 10 anos têm dificuldade para formar o conceito de decomposição, pois ainda precisam construir o conceito 
de vida, particularmente a vida dos microrganismos. Para eles inicialmente não há separação entre os microrganismos e a matéria orgânica em decomposição. E, quando por volta dos 12/13 anos, conseguem fazer esta separação, muitas vezes ainda explicam o aparecimento de fungos e bactérias pautados por uma concepção de geração espontânea. $\mathrm{O}$ autor aponta o paralelismo entre as concepções dos alunos e o desenvolvimento histórico dos conceitos de vida e reprodução como um dos subsídios ao trabalho da professora, no sentido de superar os obstáculos enunciados.

\section{As alternativas sugeridas para a questão}

Diante da constatação de que vem aumentando muito o consumo de bens e o conseqüente descarte de resíduos, além de abordar a questão da disposição, como fizemos até aqui, vem sendo consensual a constatação de que é preciso minimizar o seu montante. Que orientações a literatura ambientalista vem propondo quanto à minimização dos resíduos?

Embora a mídia e certos projetos educativos freqüentemente sugiram que a solução para reduzir a quantidade de resíduos seja a reciclagem, a literatura mais recente (AGENDA XXI, 1994) recomenda a reciclagem como o último dos chamados $3 R$ s, precedida pela redução do consumo e do desperdício e da reutilização dos produtos. O princípio dos 3Rs (Redução, Reutilização e Reciclagem) recomenda uma hierarquia da atividade que provoca menos impacto ambiental (a redução) para a que provoca maior impacto ambiental (a reciclagem), conforme GRIMBERG e BLAUTH (1998). Causamos, por exemplo, menos impacto ambiental eliminando o consumo de descartáveis (filtro de café e guardanapos de papel, fraldas, canudos, copos plásticos) do que reciclando ou reutilizando tais produtos. A reciclagem de qualquer material implica em impactos, pelo gasto de energia no processo industrial e no transporte dos materiais recicláveis, pelos recursos naturais adicionais no caso dos materiais que requerem adição de matéria prima e por ser uma atividade poluente ${ }^{10}$.

${ }^{10}$ Ver, para se ter um quadro mais completo dos impactos ambientais decorrentes da reciclagem, GRIMBERG e BLAUTH, 1998, p. 13. 
É importante observar, diante da insistência da mídia na reciclagem, que mesmo quando idealmente os resíduos de uma pessoa ou cidade sejam minimizados, passando pelos 3Rs, sempre restarão sobras (lixo), que precisarão ser destinadas, preferencialmente, a um aterro sanitário. Ressaltamos, portanto, que é fundamental abordar, numa programação educativa sobre resíduos, a questão das alternativas reais e ideais para "o que sobra".

Se os materiais analisados tocam no problema da quantidade de lixo que vem aumentando, muitas vezes sem destinação ou tratamento adequados, é preocupante a abordagem veiculada sobre as alternativas sugeridas para a resolução da questão. A reciclagem é, em metade dos recursos analisados (LD1, LD2, PD1, PD2, PD3 e R2), a solução proposta para a questão do lixo. Três dos cinco títulos de paradidáticos da amostra incluem a palavra "reciclagem", indicando tal ênfase. Os trechos abaixo ilustram o enaltecimento da reciclagem:

A reciclagem dos materiais, ou seja, separar e recuperar dos lixos certos materiais como o papel, o plástico, as latas e os materiais orgânicos que possam ser reutilizáveis, é uma solução para este problema. (LD4, p. 128).

Olhe o lixo da sua casa e faça uma lista do que encontrou lá. Dessa lista, separe o que poderia ser reaproveitado. Esse processo de utilizar os materiais usados é chamado de reciclagem. (LD2, p. 71).

Jogar fora pura e simplesmente as coisas que não usamos mais não só polui o meio ambiente como desperdiça as preciosas matérias-primas da Terra. A reciclagem está sendo vista como importante solução para esses problemas. (PD2, p. 3).

A saída ideal está na reciclagem e na montagem de usinas geradoras de energia (R2, p. 62).

Diante da prevalência desse tipo de abordagem, optamos por buscar, nesta análise, os diversos elementos dos conteúdos apresentados sobre a reciclagem, para que um aprofundamento sobre o tema possa contribuir para a superação das dificuldades e proposição de abordagens menos ingênuas e mais fundamentadas.

Iniciaremos apontando uma confusão terminológica freqüente, que evidencia uma confusão conceitual. Em dois dos materiais citados acima, os livros didáticos LD2 e LD4, a indicação da reciclagem como solução primeira agrava-se pela utilização dos termos reutilização e reaproveitamento como sendo 
sinônimos de reciclagem. Igualar os dois termos é incorreto e encobre a diferenciação entre reutilizar e reciclar, ações que causam diferentes tipos de impactos ambientais. A reciclagem de resíduos é um processo de transformar, por ação humana (reciclagem industrial ou artesanal), determinado recurso em um novo produto. Apesar de utilizar menor quantidade de matéria-prima virgem, implica em utilização de recursos (energia, água e outros) e em diferentes graus de degradação ambiental (exceto a compostagem). Já a reutilização é a utilização de um produto na sua forma original (ART, 1998, p. 451), como usar o verso de um papel, representando um impacto ambiental muito menor do que o gerado pela reciclagem, pois não utiliza recursos naturais adicionais.

O uso indiscriminado dos termos reaproveitamento/reutilização e reciclagem não é exclusividade dos livros didáticos, estando presente também nos PD2 e PD4. Ao informar que a reciclagem não é uma novidade, o PD2 exemplifica: "Durante anos, roupas velhas e outros objetos usados eram revendidos nos bazares de pechincha e lojas de caridade." (p. 12).

O mesmo paradidático remete a uma questão central quando o tema é a reciclagem: o lugar das tecnologias. Apesar de o autor mencionar algumas questões referentes aos hábitos de consumo que geram lixo desnecessariamente (PD2, p. 8 e 10), destaca as tecnologias relacionadas à reciclagem (carro reciclável, transformação de lixo tóxico da produção de fitas de vídeo em fertilizantes, energia produzida a partir do lixo e garrafas biodegradáveis, dentre outras) como solução para o problema do aumento da quantidade de lixo que tem-se gerado. Esta é uma idéia bastante difundida pelos meios de comunicação, apesar dos alertas de diversos autores e documentos nacionais e internacionais a respeito do excesso de confiança na tecnologia que os seres humanos vêm desenvolvendo para tentar equacionar os problemas ambientais (AGENDA XXI, 1994; BRASIL, 1997; GORE, 1993). A mensagem, no caso deste paradidático, seria a de que as pessoas poderiam continuar consumindo bens e até aumentando o consumo, pois o desenvolvimento de novas tecnologias de reciclagem e de produção de materiais biodegradáveis, assim como o aproveitamento de energia, resolveria a questão de, se não eliminar o lixo, diminuí-lo. Entretanto, entende-se que, se é preciso aumentar o consumo de bens básicos, no caso dos países e das camadas mais pobres, que não têm tido acesso a eles, é consensual hoje na literatura ambientalista que os países e as camadas mais ricas devem diminuir e/ou mudar hábitos de consumo, como aponta o LD4: "À medida que compreendemos que o problema do lixo não se resolverá apenas com novas tecnologias, aparece a importância de trabalharmos por uma nova mentalidade que produza atividades diferentes, que eduque e modifique hábitos." (p. 131). 
Entretanto, a necessidade de repensar valores e hábitos é secundarizada em boa parte dos recursos da amostra. Muitas vezes, as mudanças não passam por repensar questões e práticas e ocorrem involuntariamente, como nos exemplos a seguir.

O LD1 reproduz a história do livro paradidático Vida de papel, em que um saquinho de pipoca que estava na lixeira com cascas de laranja, latas e vidros é repentinamente separado e reciclado para se tornar papel branco. A seleção e encaminhamento para a reciclagem são feitos de forma involuntária, sem que ninguém reveja seus hábitos de consumo e de destinação do lixo, ou tenha o trabalho de separar os resíduos e encaminhá-los para a reciclagem. Tal mágica, nesse livro, só pode ser feita na chamada usina de reciclagem (que na verdade não recicla, e sim é o local onde pessoas separam os resíduos), indicada posteriormente no livro como local privilegiado para uma excursão.

É também por esforço involuntário que no PD1 a população se envolve com o encaminhamento de resíduos para a reciclagem. É louvável neste material a escolha do saci, personagem do folclore brasileiro conhecido por suas molecagens, como o herói da trama. A travessura do saci consiste em tirar do lixão os resíduos que poderiam ser recicláveis ou compostáveis. Achando que estava atrapalhando, ele acaba ajudando a cidade, que passa a coletar separadamente os materiais e encaminhá-los para a reciclagem. Portanto, num passe de mágica do saci, a população instituiu e começou a participar da coleta seletiva e extinguiu o lixão. A trama central sugere também, infelizmente, que um programa de coleta seletiva pode eliminar completamente o lixo.

Se hoje conseguíssemos idealmente reduzir ao mínimo o desperdício e o consumo, reutilizar e reciclar todos os resíduos possíveis, ainda restaria lixo, como o papel higiênico e objetos feitos de materiais para os quais não há tecnologia para a reciclagem (tais como couro, lâmpada, espelho, tecido, isopor, espuma e fralda descartável). Além disso, algumas tecnologias de reciclagem (como as embalagens longa-vida e as de madeira) não são acessíveis para boa parte das cidades.

Concepções acríticas sobre o envolvimento das pessoas com programas de coleta seletiva, como acima apontadas, podem difundir a idéia de que são desnecessários esforços individuais, coletivos ou governamentais para mudar hábitos ou implantar políticas, como, por exemplo, programas de coleta seletiva e reciclagem.

O PD2 foi o único dos recursos analisados que tratou adequadamente a questão da participação das pessoas nos programas, recomendando a separa- 
ção prévia dos resíduos (o que chamamos de descarte seletivo) pela população como a alternativa mais indicada (p. 14-5).

De uma forma geral, encontramos na R1 uma posição mais equilibrada sobre a reciclagem, com a abordagem da questão do desperdício e de aspectos do consumismo e a problematização do custo e responsabilidade pela reciclagem, que é apontada como desejável, junto com outras medidas de tratamento de resíduos e mesmo de políticas para o setor.

Um outro aspecto a comentar sobre a reciclagem diz respeito ao mercado para os produtos recicláveis. A falta de compradores para os resíduos pode inviabilizar programas de coleta seletiva em escolas e cidades, e é um aspecto aos quais os recursos didáticos deveriam atentar especialmente. Aqui deveria valer a orientação de que os materiais didáticos contemplassem as peculiaridades locais, abordando de alguma forma a limitação de mercado dos materiais recicláveis. As restrições ao mercado de recicláveis dizem respeito inclusive aos resíduos já convencionalmente tidos como passíveis de reciclagem: papel, plástico, vidro e metais. Muitas vezes não há quem compre plásticos ou vidro na cidade. Às vezes as limitações são sazonais, o que talvez dificulte ainda mais o programa, pois ora o vidro tem mercado, ora não tem. Isto significa que a escola que arrecadou vidro não terá como escoá-lo e explicar aos alunos (ou eles descobrirem por si) que o vidro irá para o lixão ou aterro, o que pode comprometer a disposição dos participantes e também o programa. Assim, os materiais impressos analisados que indicam ao público a possibilidade de dispor e coletar seletivamente para encaminhar para a reciclagem (LD1, LD2, LD4, LD5, PD2, PD3 e R2) deveriam dar indicações da sazonalidade do mercado, apontando para a necessidade do levantamento das possibilidades em cada região. O livro que mais se aproxima desta orientação é o PD3, que coloca exemplos de coleta seletiva em quatro cidades, Oregon, Londres, Grenoble e, maior dos méritos para um livro traduzido, inclui uma cidade brasileira, São Paulo. Este livro acerta também ao apontar que centros de reciclagem "têm tido pouco progresso na reciclagem de plásticos" (p. 17), pois este material é de difícil escoamento nos programas de coleta seletiva. Pena que, contraditoriamente, indique de maneira genérica que "você poderia ajudar o meio ambiente, guardando suas embalagens plásticas e levando-as para serem recicladas” (p. 16), quando o mais indicado seria anteceder esta sugestão por "se na sua cidade o plástico é reciclado, você poderia..."

Outra idéia sobre a reciclagem que podemos encontrar permeando o senso comum, mas que deve ter um tratamento mais criterioso nos recursos didáticos, é a de que não é preciso adicionar matéria-prima virgem na produção de recicláveis. Se é possível fazer outra lata de alumínio a partir de uma 
lata de alumínio e outra garrafa de vidro a partir dos cacos de uma garrafa de vidro, o mesmo não acontece com o papel e o plástico, que requerem, para ser reciclados, matéria-prima virgem, além dos resíduos. Assim, é incorreto afirmar, como faz a autora do LD5, transcrevendo um trecho confuso de uma reportagem da revista Claudia, que reciclar é "retirar o vidro, a resina plástica, a bauxita, o metal e a celulose da garrafa, da embalagem de plástico, da lata e do papel para produzir outros bens sem precisar adicionar matériaprima virgem." (p. 79)

Comentaremos, na seção seguinte, alguns aspectos formais e outros conceituais, mais pontuais, não discutidos nas seções sobre causas, consequências e alternativas para a questão dos resíduos.

\section{Questões formais e conceituais - alguns comentários}

Os livros didáticos analisados foram todos escritos por autores brasileiros, um ponto positivo, que propicia o conhecimento de certos aspectos de nossa realidade. Já os livros traduzidos apresentam dificuldades, como é o caso de dois dos livros paradidáticos analisados (PD2 e PD3). Apesar de oferecerem certas informações atualizadas e críticas a respeito da redução do consumo e desperdício, afirmam erroneamente que "o lixo de nossas casas geralmente é colocado em aterros sanitários”. (PD2, p. 8)

Tal afirmação é falsa para a maioria dos municípios brasileiros, pois só uma minoria deles possui aterros sanitários, sendo que $68,5 \%$ do lixo coletado no Brasil é destinado aos lixões a céu aberto.

Dentre as sugestões propostas pelo PD3 para reduzir/reutilizar estão "apagar as luzes e o ar condicionado nos cômodos que não estão sendo usados; use um agasalho extra ao invés de ligar o aquecedor de ambiente e use, sempre que puder, produtos feitos com papel reciclado” (p. 42). Infelizmente, praticamente não há oferta de venda de papel reciclado no Brasil. Aquecedores de ambiente são praticamente inexistentes (e desnecessários) em nosso país e, como os condicionadores de ar, só são usados por pessoas mais ricas, distinção omitida.

Um erro comumente encontrado em materiais impressos sobre resíduos é a classificação do papel como material inorgânico: "Esta é uma história diferente sobre o lixo, onde o plástico, o vidro, a lata, o papel (lixo inorgânico) 
e o resto de alimento (lixo orgânico) ganham vida e aparecem como personagens...” (PD4, p. 7). Parece que o erro acontece porque o papel é o único dos resíduos recicláveis que é orgânico, mas é uma distração grave, à qual se deve atentar.

Julgamos que alguns dos erros percebidos nos recursos analisados são provavelmente decorrentes da falta de uma revisão cuidadosa dos textos. É o caso do LD4, que ao sugerir a confecção de papel reciclado tem como um dos passos "colocar a mistura triturada na boca" (p. 130), ao passo que a figura que acompanha esta orientação mostra a mistura de papel triturado e água sendo despejada numa bacia, e não boca.

Conforme CARVALHO (1996), deveriam ser considerados os diferentes aspectos referentes ao ambiente, incluindo os sociais, econômicos e políticos. Consideramos que os interesses de diferentes grupos ou classes sociais estão em jogo quando a bandeira da defesa do meio ambiente é levantada. Tal é o caso de algumas empresas, mais interessadas em reverter por meio do marketing sua imagem negativa, de causadora de danos ambientais, do que de fato responsabilizar-se por modificações significativas quanto à diminuição ou erradicação dos impactos de suas atividades. Ilustra-se esse argumento com o caso da Dow Química, que juntamente com outra empresa recebe um tratamento especial no PD3, no quadro $O$ incentivo da indústria, que elogia um programa de redução de lixo lançado por essa empresa. Talvez o elogio não chamasse tanto a atenção se em outro quadro do PD3, Desastres com o lixo, as empresas responsáveis pelos graves acidentes listados fossem também nomeadas. Todos os acidentes mencionados foram decorrentes das atividades de indústrias de produtos químicos (identificamos a Chisso-Minamata, ICMESA e Union Carbide). O elogio à Dow ${ }^{11}$, talvez a maior indústria lançadora de dioxina (um produto altamente tóxico e carcinogênico para os animais), em um livro que pretende informar sobre as questões ambientais, é estarrecedor. Não se pode tratar de uma questão ambiental (resíduos sólidos) de forma isolada de outras questões ambientais (poluição/acidentes com substâncias tóxicas por indústrias). $\mathrm{O}$ fato de uma indústria ter um programa de reciclagem ou minimização de resíduos não tóxicos não significa que tenha uma preocupação genuína com as questões ambientais.

\footnotetext{
${ }^{11}$ Sobre as atividades da Dow Química e dioxinas, ver www.greenpeaceusa.org/toxics/
} 


\section{Discussão e considerações finais}

A análise permitiu identificar que na maioria dos recursos os autores problematizam o aumento da quantidade de lixo, o que é um aspecto positivo. Significa que a abordagem do lixo nos materiais analisados não vem se reduzindo, como era comum aos livros didáticos de alguns anos atrás, à orientação de que o que não nos serve mais deve ser colocado em latas ou lixeiras. Embora boa parte de nós brasileiros ainda joguemos fora de lugar o que não nos serve mais (e o desafio de como lidar com o problema não deve ser abandonado), já sabemos da importância de abordar o tema dos resíduos em seus demais aspectos ambientais, passando pelos nossos hábitos insustentáveis de consumo (que empregam recursos naturais e poluem), e pela possibilidade de propagação de doenças ou contaminação da água e do solo.

Entretanto, infelizmente quase todos os recursos apresentam equívocos na proposição de alternativas para a questão, já que as soluções tecnológicas são apontadas como a alternativa principal a este aumento. Tais soluções envolvem diferentes aspectos da reciclagem, como apontamos. Poucos dos recursos didáticos analisados questionam o consumismo e/ou apontam caminhos individuais ou coletivos para pensá-lo. O consumo é visto como inevitável, restando-nos investir em tecnologias para reciclagem. É uma posição fatalista diante do consumismo, em que a reciclagem tem como função aliviar a consciência do consumidor, que teria seus resíduos reciclados.

Consideramos que as abordagens enaltecedoras da reciclagem são fruto de uma perspectiva utilitarista da natureza (CINQuetTI, 2002). Assim, é mais fácil perceber (e ensinar sobre) o retorno para o ser humano da reciclagem, em que o produto "volta" sob outra forma, do que perceber o retorno, em produto ou benefício, da redução do consumo e do desperdício. Pensamos que superar a perspectiva utilitarista representa um dos desafios da Educação Ambiental.

Alguns recursos analisados sugerem que a reciclagem de resíduos pode ser realizada sem uma intencionalidade por parte das pessoas e, como num passe de mágica, os resíduos seriam reciclados sem que se repensassem hábitos de consumo e se modificassem atitudes.

Ainda sobre a reciclagem, à exceção de um livro paradidático, os demais recursos ignoram questões relativas às limitações locais ou regionais (mercado, tecnologias disponíveis, existência de programas de coleta seletiva), o que pode inviabilizar ações de educação e gestão ambiental quanto ao descarte, à coleta seletiva e à reciclagem. 
Nos recursos que abordam o tempo de degradação dos materiais no ambiente há grande disparidade nos números apresentados, indicando a necessidade de pautar-se por informações que considerem as diferentes características ambientais em que os materiais se decompõem e também resultados de trabalhos versando sobre o tempo de degradação dos materiais em aterros sanitários, como os de RATHJE $(1989 ; 1991)$.

Um tema pouco freqüente em toda a amostra é o das substâncias tóxicas presentes no lixo domiciliar. A discussão deste tema só foi encontrada nos artigos de revistas. Vivemos um momento propício para abordar este aspecto da questão para o interior da escola, pois temos uma legislação recente que proíbe o descarte de pilhas e baterias e obriga as fábricas a coletar esses produtos para ser reciclados ou encaminhados a aterros industriais. Outras substâncias tóxicas de uso residencial freqüente deveriam ser introduzidas na discussão, como as tintas e lâmpadas fluorescentes.

Encontramos orientações, conceitos e informações que consideramos incorretos tendo como referencial a literatura científica e documentos nacionais e internacionais. Dentre essas incorreções, destacam-se a recomendação da queima do lixo, a classificação do papel como inorgânico, o conceito de reutilização igualado ao de reciclagem e a afirmação de que a maior parte do lixo é destinada a aterros sanitários, o que não procede no caso brasileiro.

Olhando comparativamente os três tipos de recursos analisados, constatamos que os erros conceituais, ausências, informações desatualizadas e posturas ingênuas frente às soluções tecnológicas foram encontrados em livros didáticos, paradidáticos e revistas, indicando, portanto, a necessidade de uma leitura e utilização criteriosa dos três tipos de recursos. Alguns livros surpreendem positivamente em certos trechos, pelo tratamento atualizado e integrado da questão ambiental (PD2, PD3, LD2, LD4 e especialmente o LD5), embora tais posicionamentos coexistam nestes recursos com algumas das inadequações citadas. Os paradidáticos não demonstram ter, considerando os critérios mencionados, qualidade superior aos livros didáticos, pois também contêm erros, ausências e posturas acríticas, verificadas nos demais tipos de recursos. As revistas apresentam poucos erros, talvez por sua natureza diversa dos didáticos e de boa parte dos paradidáticos, que têm o compromisso de apresentar e desenvolver conceitos básicos tais como reutilização, reciclagem, degradação e orgânico/inorgânico. Entretanto prevalecem, também nas revistas, posturas pouco críticas quanto ao lugar das tecnologias associadas ao lixo, embora com o mérito de abordar temas mais atualizados, ausentes nos outros dois tipos de recursos, como é o caso do risco de contaminação oriunda de pilhas e baterias. Apesar dos méritos e do seu caráter, mais complementar e menos 
freqüente no uso em sala de aula, se comparadas aos paradidáticos, as revistas não devem deixar de ser analisadas pelas professoras com olhar crítico.

Quanto ao enaltecimento das tecnologias associadas à reciclagem, pensamos que, como outros temas ambientais, as informações científicas deveriam ser compreendidas num campo mais amplo da revisão de valores éticos entre ser humano e natureza e entre os seres humanos (REIGOTA, 1997), assim como da elucidação dos mecanismos de produção do conhecimento científico nas sociedades (CARVALHO, 1996). Corremos o risco, se não tivermos esta compreensão, de reproduzirmos nos recursos didáticos discursos que pouco ou nada mudarão o enfrentamento das questões ambientais.

Nossas análises sugerem que educadoras interessadas ou envolvidas com a temática ambiental devem compreender que o tipo de conhecimento que precisam buscar deve ser permeado de constantes indagações de cunho científico, ideológico e político. Cabe perguntar quem faz o discurso, quem financia quem faz o discurso e que interesses econômicos e políticos tais segmentos podem ter. No caso dos recursos analisados, em que é difícil estabelecer tais interesses, é possível que informações e posicionamentos advindos de determinados segmentos (indústria de vidro, plástico, de materiais recicláveis) sejam tomados como neutros e assim inseridos nos recursos didáticos. Apesar deste primeiro cuidado, de perguntar-se a quem interessa a informação veiculada, não podemos concluir linearmente que toda informação veiculada pela indústria, por exemplo, é incorreta ou omissa. Talvez a melhor atitude seja o constante exercício de perguntar-se, a cada informação, se pode ser considerada confiável, tentando continuamente buscar respostas, sabendo-as provisórias.

Entendemos que a reflexão sobre os materiais didáticos deva estar presente desde a formação inicial. Seria na escola, entretanto, diante das demandas prementes da prática, que esta atividade se intensificaria. Neste sentido, observamos a importância das iniciativas institucionais das escolas de preverem momentos de análise e reflexão sobre os materiais.

Dentre as dúvidas, é importante, para não nos prostrarmos numa postura imobilizadora, ancorarmo-nos em algumas certezas, que hoje proporíamos que fossem:

- destacar a redução/modificação dos hábitos de consumo e a redução do consumo e do desperdício em primeiro lugar e a reutilização de materiais em segundo;

- inserir a reciclagem como o último dos "3Rs": importante, mas não à frente das outras duas ações;

- dimensionar as soluções tecnológicas para as questões ambientais, num quadro em que mudanças nas relações entre o ser humano e a 
natureza e entre os seres humanos sejam tão (ou mais?) essenciais quanto as tecnologias.

Nossos achados sobre os recursos didáticos concordam com críticas já feitas a programas educativos de reciclagem (BLAUTH, 1994), particularmente sobre os limites da tecnologia e a falta de discussão do consumismo. Pensamos que muitas das críticas aqui feitas podem nortear a seleção e elaboração de recursos didáticos, assim como as diretrizes para uma programação educativa sobre lixo, resíduos, reciclagem e sobre a temática ambiental.

\section{REFERÊNCIAS}

AGENDA XXI. Brasília: Editora do Senado, 1994.

AMERICAN ASSOCIATION FOR THE ADVANCEMENT OF SCIENCE. Benchmarks for Science Literacy. New York: Oxford University Press, 1993. 418 p.

ART, H. W. (Ed.). Dicionário de Ecologia e Ciências Ambientais. São Paulo: Melhoramentos, 1998. $583 \mathrm{p}$.

BLAUTH, P. Os resíduos educativos dos programas de reciclagem. Jornal USP, 14 ago. 1994.

BONAZZI, M.; ECO, H. Mentiras que parecem verdades. São Paulo: Summus, 1980.

BONFIGLIOLI, C. P.; LISBOA, M. Pilhas usadas: o que fazer com elas? Debates Socio Ambientais, v. 2, n. 7, p. 29-30, 1997.

BRASIL. Ministério da Educação e Cultura. Parâmetros curriculares nacionais: meio ambiente/saúde. Brasília, 1997.

CARVALHO, L. M. A temática ambiental e a escola de $1^{\circ}$ grau. São Paulo, 1989. Tese (Doutorado) - Universidade de São Paulo.

CARVALHO, L. M. A temática ambiental e a formação de professores. In: BICUDO, M. A. V.; SILVA JÚNIOR, C. A. Formação do educador: dever do Estado, tarefa da universidade. São Paulo: Universidade Estadual Paulista, 1996.

CEMPRE INFORMA. São Paulo, Cempre, n. 42, nov./dez. 1989. 4 p.

CARVALHO, L. M. et al. Conceitos, valores e participação política. In: TRAJBER, R.; MANZOCHI, L. H. Avaliando a Educação Ambiental no Brasil. São Paulo: Gaia, 1996, p. 77-119. 
CINQUETTI, H. C. S. Educação ambiental e resíduos sólidos. Araraquara, 2002. Tese (Doutorado em Educação) - Faculdade de Ciências e Letras, Unesp.

CINQUETTI, H. C. S.; CARVALHO, L. M. As professoras e os conhecimentos sobre resíduos sólidos. ENCONTRO DE PESQUISA EM EDUCAÇÃO AMBIENTAL, 2 ., 2003, UFSCAR, São Carlos.

EMBRAPA. Atlas do meio ambiente do Brasil. Brasília: EMBRAPA - SPI: Terra Viva, 1996.

FIGUEIREDO, P. J. M. A sociedade do lixo. Piracicaba: Editora Unimep, 1995.

GORE, A. A Terra em balanço. São Paulo: Augustus, 1993. 447 p.

GRIMBERG, E.; BLAUTH, P. (Coords.). Coleta seletiva. São Paulo: Pólis, 1998. $104 \mathrm{p}$.

IBGE - Instituto Brasileiro de Geografia e Estatística. Pesquisa Nacional de Saneamento Básico. Disponível em: <http://www.ibge.gov.br/home/presidencia/noticias/ 27032002 pnsb.shtm> Acesso em: 17 dez. 2003.

JARDIM, N. S et al. (Coords.). Lixo municipal - manual de gerenciamento integrado. São Paulo: Instituto de Pesquisas Tecnológicas do Estado de São Paulo: Cempre, 1995.

LOGAREZZI, A. Por uma terminologia consistente em resíduos. 2003. (Não publicado).

PRETTO, N. L. As ciências nos livros didáticos. Campinas: Unicamp; Salvador: UFBA, $1995,95 \mathrm{p}$.

NOSELLA, M. L. D. As belas mentiras: a ideologia subjacente aos textos didáticos. São Paulo: Moraes, 1980.

RATHJE, W. Rubbish! The Atlantic Monthly, p. 99-109, Dec. 1989.

RATHJE, W. Once and future landfills. National Geographic, p. 116-134, May 1991.

REIGOTA, M. Meio ambiente e representação social. São Paulo: Cortez, 1997.

SILVA, R. A. Compostagem de baixa qualidade e riscos à saúde. Consumo, lixo e meio ambiente. São Paulo: Secretaria do Meio Ambiente, 1997. 31 p.

SOSSAI, J. A. et al. Avaliação de textos utilizados por professores de $1^{\circ}$ grau como apoio para atividades de Educação Ambiental. Revista Brasileira de Estudos Pedagógicos, v. 78, n. 188/189/190, p. 124-156, jan./dez. 1997.

TRAJBER, R.; MANZOCHI, L. H. (Coords.). Avaliando a educação ambiental no Brasil: materiais impressos. São Paulo: Gaia, 1996. 226 p. 
TRIVELATO JÚNIOR, J. Um obstáculo à aprendizagem de conceitos em biologia. In: NARDI, R. (Org.). Questões atuais no ensino de ciências. São Paulo: Escrituras, 1998, 104 p., cap. 8, p. 77-84.

Texto recebido em 10 fev. 2004

Texto aprovado em 23 abr. 2004 